\title{
Building on the rich heritage of the Medical Journal of Australia
}

$\mathrm{T}$ he Medical Journal of Australia is without doubt the most important general medical journal in Australia, with a history dating back over 100 years. It is therefore a great honour and privilege to commence as your new Editor-in-Chief.

My professional interests span clinical practice, medical education and research, medical leadership, health policy and social justice. My goals as editor are to build on the outstanding DNA of the Journal, further increasing its relevance and readability, and attracting the highest quality submissions. We will aim to build on the Journal's rich heritage by continuing our practice of publishing the best clinical science papers that have the potential to transform practice, including clinical trials and comparative effectiveness research. We will also aim to inform readers on advances in medical education, and cover issues from medical leadership to re-engineering our health system. We will continue to seek expert reviews, editorials and commentaries, meta-analyses and guidelines, and the latest news and information that everyone in practice needs to know. It is my goal to reinforce the unique role that the Journal plays as the pre-eminent publisher of Australian medical research and as a vital platform for translating research into practice, as well as helping to inform the broader health policy debate. This is part of the Journal's success and why it is relevant to clinicians, researchers and academics across the nation.

The MJA is prestigious and influential, but another advantage to publishing with us is that much of the content including our research content is published freely on our website at mja.com.au, without the waiting period often imposed by other journals. I can also assure readers that as Editor-in-Chief, I have a guarantee of editorial independence and I will fiercely guard this independence on your behalf. For the nearly 32000 subscribers who receive the $M J A$ in print, and the many others who read the Journal online, the team will work tirelessly to provide the best medical journal experience possible.

We live in a world that, in terms of connectivity through social media, is rapidly shrinking, and the $M J A$ has an important role to play not just nationally but globally. We will therefore now be encouraging locally relevant international articles. And we will continue to tackle in our pages articles that highlight the tough health issues we all face and provide possible solutions, from the health needs of Indigenous Australians to the health impacts of global migration, population growth, dwindling resources, an ageing population and climate change, to name a few. We will

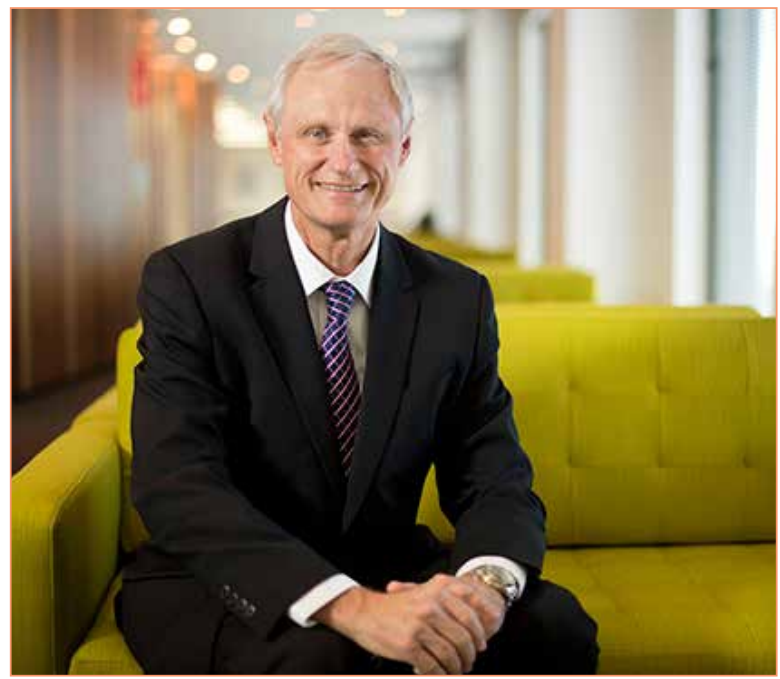

look both out to the world and across Australia to find the objective data that can help guide us all. We will seek balance among the many expert opinions and will aim at all times to be rigorous, evidence-based and transparent.

Whether any of us like it or not, our performance in medicine is being increasingly measured and critiqued, and it's no different for medical journals. Clinicians and academics want to publish in the best medical journals and one metric applied universally is the impact factor, calculated by counting the mean number of citations received per article published during the previous 2 years. In the best journals, editors arguably "live and die" by the journal impact factor published each year. The impact factor is flawed (some argue fatally so) and is not used by the National Health and Medical Research Council; but it can't be ignored either! $!^{1,2}$ In 2015, the MJA, your national journal, ranks in the top 20 general medical journals

MJA impact factor, 2009-2014

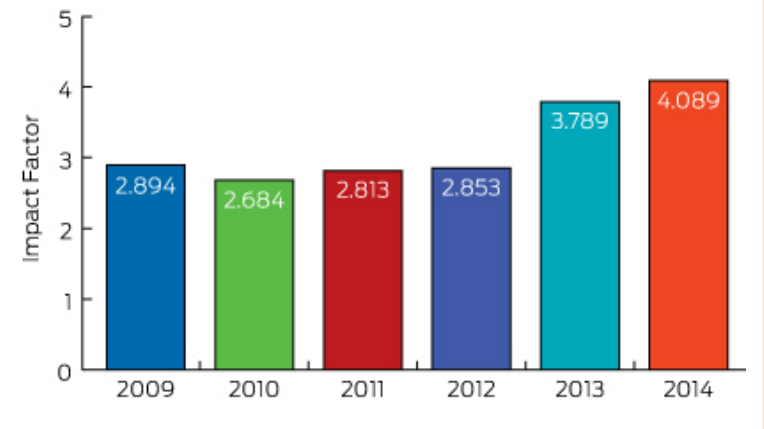


Podcast and video with Professor Nick Talley available at www.mja.com.au/ multimedia/podcasts and iTunes. worldwide and has a highly respectable impact factor of 4.089 (Box, previous page). I am pleased to say that the impact factor of the $M J A$ has risen and I anticipate over the coming years that it will continue to rise (as will other metrics of excellence) as we further increase the quality and reach of what we publish.

We welcome your best work being submitted for consideration. Our acceptance rate is currently falling (as marks all of the best medical journals) but I can pledge that your medical articles will be expertly peer reviewed and edited before publication. The editorial team will do its utmost to ensure it makes the best possible decisions, and we will work hard with authors to help them publish polished, excellent contributions.
Finally I would like to acknowledge and thank Professor Charles Guest in his capacity as Interim Editor-in-Chief for his stewardship of the Journal in the second half of 2015. He has been instrumental in supporting our editors and maintaining the continuity and the quality of the Journal.

Thank you for reading the MJA. You can expect that the Journal will be further increasing its scientific reputation and international presence over the next few years, and I hope you will be part of it if you have a contribution you wish to make. We welcome suggestions and feedback so we can further improve the Journal on your behalf. I am committed to strengthening your clinical practice through its pages and look forward to our journey together. 
1 Walter G, Bloch S, Hunt G, Fisher K. Counting on citations: a flawed way to measure quality. Med J Aust 2003; 178: 280-281. https://www.mja.com.au/journal/2003/178/6/countingcitations-flawed-way-measure-quality

2 Smart P. Is the impact factor the only game in town? Ann R Coll Surg Engl 2015; 97: 405-408. 